\title{
Prática didática: entre a programação, a manipulação e o ajustamento
}

DOl: http://dx.doi.org/10.21165/el.v50i2.2869

\section{Eliane Soares de Lima'}

\section{Resumo}

São as transformações que se impuseram à prática didática dos professores em face do discurso da mudança fortalecido pelos PCNs (1998) e, mais recentemente, pela BNCC (2018) o que nos interessa discutir. Nesse sentido, propomos apresentar, com base na perspectiva da Semiótica Discursiva e da Sociossemiótica, uma racionalização da atividade docente concebida enquanto prática semiótica, ou seja, como ação que constrói no seu desenrolar a significação de uma situação regida por códigos de conduta, normas e procedimentos (pré-)estabelecidos. Para isso, examinaremos as mudanças ocorridas na dinâmica de funcionamento narrativo da perspectiva didático-pedagógica tradicional a esta que se tem reconhecido como renovada. Esperamos com isso colaborar de alguma forma com a necessidade de esclarecimento e divulgação sobre o assunto, mostrando que na base dessa tão reivindicada transformação da prática didática na Educação Básica está a passagem da aula como percurso do ensinar, da performance do Sujeito-professor, ao percurso da aprendizagem, do Sujeito-aluno, ou seja, do monólogo ao diálogo, à construção conjunta de habilidades e competências.

Palavras-chave: ensino; prática didática; regimes de interação; semiótica.

1 Universidade de São Paulo (USP), São Paulo, São Paulo, Brasil;

li.soli@usp.br; http://orcid.org/0000-0002-0198-4473 


\title{
Didactic practice: between programming, manipulation, and adjustment
}

\begin{abstract}
This paper aims at explaining the transformations that have been imposed on the didactic practice of Brazilian teachers in the light of the discourse of change strengthened by Brazil's Parâmetros Curriculares Nacionais (1998) and, more recently, by the Base Nacional Comum Curricular (2018). To do this, we present, in the framework of Discursive Semiotics and Sociosemiotics, a rational view of teaching activity conceived as a semiotic practice, in other words, an action that builds in its unfolding the meaning of a situation governed by codes of conduct, norms and (pre-)established procedures. To that end, we will examine the changes that occurred in the dynamics of narrative functioning from a traditional didactic-pedagogical perspective to this renewed one. We hope to collaborate thus with the need for clarification and dissemination on this topic, showing that this much-demanded transformation of teaching practice in Basic Education lies on the shifting from the class as a teaching path of the teacher-subject's performance, to the learning path of the student-subject, that is, from monologue to dialogue, to the shared construction of skills and competences.
\end{abstract}

Keywords: teaching; didactic practice; forms of interaction; semiotics.

\section{Da prática didático-pedagógica tradicional à renovada}

Nos discursos acerca da atividade docente de ontem e hoje constata-se uma tensão entre duas perspectivas distintas, bem como a necessidade de mudança no comportamento didático do professor: passa-se a combater a prática pautada pela pedagogia tradicional, na qual o professor é o detentor do saber, com a ação educativa vista apenas como transmissão de saberes aos que nada sabem, para defender uma prática didáticopedagógica renovada², em que o aluno é quem deve ser o centro da ação, o protagonista do processo de ensino-aprendizagem, que passa a ser encarado como aprofundamento, uma ampliação daquilo que o aluno já sabe e deve ainda saber para uma plena inserção social. Nas palavras de Libâneo (2011, p. 30):

O ensino exclusivamente verbalista, a mera transmissão de informações, a aprendizagem entendida somente como acumulação de conhecimento, não subsistem mais. Isso não quer dizer abandono dos conhecimentos sistematizados da disciplina nem da exposição de um assunto. O que se afirma é que o professor medeia a relação ativa do aluno com a matéria, inclusive com os conteúdos

$2 \mathrm{~A}$ escolha dos termos se fez com base nas duas concepções pedagógicas que são conhecidas como "Pedagogia Tradicional" e "Pedagogia Renovada" (LIBÂNEO, 2013). 
próprios de sua disciplina, mas considerando os conhecimentos, a experiência e os significados que os alunos trazem à sala de aula, seu potencial cognitivo, suas capacidades e interesses, seus procedimentos de pensar, seu modo de trabalhar.

É verdade, no entanto, que mais do que uma discussão mais esclarecedora - porque mais operativa do ponto de vista da ação didática em ato - sobre essa necessária transformação da atividade docente, do novo papel do professor em sala de aula, ou do que isso representa de fato, o que constantemente se tem em todos esses discursos que defendem a renovação é um modo de ver e pensar criticamente a questão. Tratase, sobretudo, de uma perspectiva mais afeita ao ponto de vista pedagógico, com uma sistematização das novas exigências colocadas ao trabalho docente, mas sem muitos subsídios à prática didática propriamente dita; estes, sim, condição fundamental à efetiva mudança de atitude por parte do professor, logo, à implementação das reformas educacionais propostas nos últimos anos.

O que exatamente implica passar do ensino como transmissão de conhecimento ao ensino como mediação do processo de ensino-aprendizagem para o desenvolvimento de competências e habilidades? O que significa na prática criar condições significativas para que esse processo ocorra de fato? Por meio de que estratégias criar habilidades cognitivas de construção e reconstrução de conceitos, atitudes e valores que aumentem a competência discursiva dos alunos? Essas são perguntas que precisam ser respondidas como forma de didatização desse modo "renovado" de conceber a prática didáticopedagógica cotidiana, dessa mudança na dinâmica de funcionamento narrativo da interação entre professor, aluno e conhecimento.

Como uma tentativa nesse sentido, para oferecer uma resposta possível, sobretudo, às duas primeiras perguntas, a intenção do estudo aqui proposto é a de desvelar os aspectos formais da prática didática, que, enquanto ação responsável pelas condições de apropriação de saberes e das formas de intervenção nas situações concretas de ensino-aprendizagem, pode ser pensada como prática semiótica. Para isso, com base na perspectiva da Semiótica Discursiva e da Sociossemiótica, primeiro lançaremos luz à estrutura narrativa que subjaz à prática didática, entendida como prática semiótica, circunscrevendo, na sequência, as noções de prática didático-pedagógica tradicional e renovada com as quais trabalharemos, para mostrar a mudança tanto nos papéis actanciais desempenhados, quanto nos regimes de interação instaurados, peça-chave na transformação hoje reivindicada. Procuraremos ainda chamar a atenção para algumas das consequências dessa renovação da prática didática, concluindo, por fim, com algumas considerações finais sobre os dados levantados.

Nossa expectativa é a de que essa investigação possa responder de alguma forma à necessidade de esclarecimento e divulgação entre os professores do ensino básico sobre a mudança imposta a sua atividade em sala de aula, facilitando a sua adaptação a essa transformação necessária. 


\section{A prática didática como prática semiótica}

Segundo Greimas e Courtés (2008, p. 380), práticas semióticas são "processos semióticos reconhecíveis no interior do mundo natural e definíveis de modo comparável aos discursos (que são 'práticas verbais', isto é, processos semióticos situados no interior das línguas naturais)", podendo ser igualmente qualificadas de sociais, pois "apresentamse como sequências significativas de comportamentos somáticos organizados, cujas realizações vão dos simples estereótipos sociais até as programações" (ibid.); os autores acrescentam ainda: "Os modos de organização desses comportamentos podem ser analisados como programas (narrativos) cuja finalidade só se reconhece a posteriori" (ibid.).

Desse modo, da situação de aula, "como conjunto dos meios e condições pelos quais o professor dirige e estimula o processo de ensino em função da atividade própria do aluno no processo da aprendizagem escolar" (LIBÂNEO, 2013, p. 195), pode-se depreender um esquema narrativo canônico, uma sucessão de etapas que mantêm, tal como propõe a Semiótica Discursiva, uma relação de pressuposição lógica: da manipulação à aquisição de competência que leva à performance, seguida, por sua vez, de uma sanção pragmática e/ou cognitiva, podendo ser ela positiva e/ou negativa. Em outras palavras, do ponto de vista modal, a prática didática - sintagmática narrativa que manifesta a intencionalidade didático-pedagógica - organiza-se, em traços gerais, como um fazer-crer que transmite ao destinatário um querer e/ou dever-fazer, seguido da doação (ou privação) de um saber e/ou poder-fazer, condição sine qua non ao fazer-ser posteriormente sancionado.

Cruzam-se nesse processo narrativo dois percursos interdependentes: o do Sujeito e o do Destinador, desdobrando-se este último em Destinador-manipulador e Destinadorjulgador. O percurso do Sujeito, conforme explica Barros (2001), constitui-se pelo encadeamento lógico do programa de aquisição de competência (pressuposto) e do programa da performance (pressuponente), ou seja, o Sujeito adquire competência modal e semântica, torna-se, assim, Sujeito competente para um dado fazer e executa-o. O percurso do Destinador-manipulador, por sua vez, determina, pelo programa da manipulação, os valores que serão visados pelo Sujeito, seja enquanto Objeto-valor buscado (programa narrativo de base), seja enquanto valor modal necessário ao fazer transformador (programa narrativo de uso, pressuposto e fundamental). Ainda de acordo com a autora (BARROS, 2001), trata-se de um programa de doação de competência ao Destinatário, que, ao aceitar os valores transmitidos, será o Sujeito do fazer. Por fim, o percurso do Destinador-julgador delineia o programa da sanção, consistindo no reconhecimento da performance do Sujeito (sanção cognitiva) que pode culminar em uma retribuição, sob a forma de recompensa ou punição (sanção pragmática). Nas palavras de Barros (Idem, p. 39), "a sanção faz eco à manipulação e ambas delimitam o percurso do sujeito, encaixando-o entre dois momentos do sistema do destinador". 
Ainda que essa formulação seja bastante abstrata, a partir dela pode-se perceber que, de fato, trata-se da dinâmica narrativa subjacente à situação de aula, enquanto espaço de interação entre o professor, os alunos e os saberes, regido pela circulação de objetos e objetivos de ensino, do que e de como ensinar, próprios à prática didático-pedagógica. Com isso em mente, examinemos a estrutura narrativa das duas práticas didáticas em pauta - a tradicional, da transmissão de conteúdos, e a renovada, do desenvolvimento de competências e habilidades - para melhor compreendermos o que muda, estruturalmente falando, de uma a outra.

\section{Entre a programação, a manipulação e o ajustamento}

Na prática didático-pedagógica tradicional, com aulas predominantemente expositivas que privilegiam a transmissão de conteúdos em uma interação professor-aluno verticalizada, sendo este último considerado tábula rasa, o processo de ensino-aprendizagem se faz em "via de mão única": o professor fala e o aluno ouve, o professor ensina e o aluno aprende. A própria definição de aula no Houaiss (2009, grifos nossos) corrobora essa visão, secular, do que seja a situação de aula:

aula [...] 2 exposição sobre determinada área de conhecimento, feita por professor e dirigida a um ou mais alunos, ger. em estabelecimento de ensino; 3 sala em que um professor leciona; sala de aula, classe; 4 classe, turma; 5 parte de um programa de ensino, no conjunto de um curso, transmitida aos alunos por professor ou por meio de textos; lição; 6 ação, gesto, palavra ou obra que constitui um ensinamento, uma lição.

Observe que praticamente nenhuma menção à aprendizagem é feita; o acento de sentido recai todo sobre a atividade de ensino, destacando o protagonismo do professor e de seu saber na ação educativa e, em contrapartida, a passividade do aluno no seu deveraprender. Nesse ponto de vista, o Sujeito da ação é o professor, em relação com seu Objeto-valor, ensinar. É esse o programa narrativo de base, com os alunos atuando como Adjuvantes - ou mesmo como Oponentes - da performance. A presença deles garante (ou impede) o poder-fazer do docente, que se soma ao saber-fazer considerado como já adquirido, porque pautado somente pelo domínio do conteúdo a ser transmitido³.

A aprendizagem em si figura, nesse sentido, como programa narrativo de uso, responsável pelas condições de realização da performance. Diante disso, os alunos passam a ser sujeitos do fazer delegados pelo Sujeito do fazer principal, o professor, estando modalizados pelo dever-fazer, independente de seu querer-fazer; eles devem aprender,

3 No quadro cada vez mais comum do recrutamento mais amplo e menos seletivo de professores, é o livro didático que passa a ocupar a função de adjuvante da aquisição de competência para o saber-fazer necessário à prática didática, não só em relação aos conteúdos a serem trabalhados, mas inclusive do modo como devem ser explorados em aula, descritos no Manual do Professor. 
e é aí que a memorização aparece como estratégia-chave do processo de ensino e aprendizagem, podendo esta última ser considerada mecânica, pois o aluno limita seu esforço a memorizar ou estabelecer relações diretas e superficiais com os conteúdos. Nas palavras de Libâneo (2013, p. 67):

\begin{abstract}
Na Pedagogia Tradicional, a Didática é uma disciplina normativa, um conjunto de princípios e regras que regulam o ensino. A atividade de ensinar é centrada no professor, que expõe e interpreta a matéria. Às vezes são utilizados meios como a apresentação de objetos, ilustrações, exemplos, mas o meio principal é a palavra, a exposição oral. Supõe-se que ouvindo e fazendo exercícios repetitivos, os alunos "gravem" a matéria para depois reproduzi-la, seja através das interrogações do professor, seja por meio das provas. Para isso, é importante que o aluno "preste atenção", porque ouvindo facilita-se o registro do que se transmite, na memória. 0 aluno é, assim, um recebedor da matéria e sua tarefa é decorá-la. Os objetivos, explícitos ou implícitos, referem-se à formação de um aluno ideal, desvinculado da sua realidade concreta.
\end{abstract}

A situação de aula nessa configuração é, portanto, um percurso narrativo do ensino, no qual a aprendizagem atua como pressuposição, como programa narrativo de uso que leva à realização do programa de base. Conforme assinalam Greimas e Courtés (2008, p. 390, grifo dos autores), "o conjunto sintagmático, assim reconhecido, corresponde à performance do sujeito", no caso, do professor. Para Portela (2008, p. 9):

Essa interação entre sujeitos tem, "a montante", a orientação persuasiva e formadora do sujeito-operador educador (ou didata) e, "a jusante", a recepção/ interpretação do sujeito educando (ou aprendiz) que, do ponto de vista do sujeito destinador da educação como um todo, ocupa a posição, por um lado, de destinatário e, por outro, de um mero "objeto", a ser transformado e predicado.

Há uma série de implicações que decorrem dessa configuração narrativa: toda a prática didática do professor é centrada no ensino em si, tendo a aprendizagem como um resultado lógico - se há ensino, logo deve haver aprendizagem; quando não há, culpa-se a incapacidade do aluno. É, por conseguinte, o dever-fazer que sobredetermina a relação do aluno com os conteúdos transmitidos. A ação didática é, então, considerada como operação, isto é, como fazer-ser, uma vez que "operar consiste em atuar a partir de fora (tipicamente, por meio de uma força) sobre a localização, a forma, a composição ou o estado de algum objeto" (LANDOSWSKI, 2014, p. 22, grifo do autor).

A atividade docente a partir dessa perspectiva é, portanto, da ordem da programação. Tal regime, para Landowski (2014), corresponde àquele governado pela regularidade, por isso absolutamente previsível; é aquele que faz-ser o estado buscado. Daí a acusação de uma lógica própria à "desumanização do ensino", uma vez que, nesse ponto de vista: 
O ensino das disciplinas segue uma ordem lógica, horários rígidos, sem considerar as diferenças de aprendizagem entre os alunos. $O$ aluno aprende diretamente do professor e do livro didático. Os problemas da vida real na sociedade (global e local), os interesses em que os alunos estão envolvidos, outras formas de saber, não se fazem presentes na sala de aula. (LIBÂNEO, 2011, p. 32).

Explica-se, assim, a frequência com que se tem criticado esse modelo didáticopedagógico por seu caráter mecanicista. Do lado oposto dessa lógica, está a prática didático-pedagógica renovada, que propõe, em contraposição à prática tradicional, uma outra forma de atuação do professor em sala de aula, na qual o objetivo de ensino não é mais a pura transmissão de conteúdos, mas a criação de condições de acesso ao saber que deve ser "autonomamente" buscado pelo aluno, importando, antes de tudo, o desenvolvimento de habilidades cognitivas (e pragmáticas) capazes de aumentar a sua competência de leitura e escrita, para que ele "aprenda a aprender". Conforme detalha Libâneo (2013, p. 68):

A Didática da Escola Nova ou Didática ativa é entendida como "direção da aprendizagem", considerando o aluno como sujeito da aprendizagem. O que o professor tem a fazer é colocar o aluno em condições propícias para que, partindo das suas necessidades e estimulando os seus interesses, possa buscar por si mesmo conhecimentos e experiências. A ideia é a de que o aluno aprende melhor o que faz por si próprio. Não se trata apenas de aprender fazendo, no sentido de trabalho manual, ações de manipulação de objetos. Trata-se de colocar o aluno em situações em que seja mobilizada a sua atividade de criação, de expressão verbal, escrita, plástica ou outro tipo. O centro da atividade escolar não é o professor nem a matéria, é o aluno ativo e investigador. O professor incentiva, orienta, organiza as situações de aprendizagem, adequando-se às capacidades de características individuais dos alunos.

Nessa configuração narrativa, a ação didática não mais se pauta apenas pelo ensino, antes o coloca a serviço da aprendizagem, sobre a qual recai agora o acento de sentido. Essa é a grande mudança. O Sujeito do percurso de ensino-aprendizagem não deve mais ser o professor, e sim o aluno. Ainda que caiba ao professor, enquanto Destinador do percurso, fazer evoluir o processo de aprendizagem, viabilizando o caminho de acesso às condições para a ação - ele faz fazer -, é ao aluno que cabe a performance, é ele o Sujeito do percurso de ensino-aprendizagem.

É importante notar, todavia, que nessa outra forma de conceber a prática educativa, mais do que no percurso do Sujeito, é no percurso do Destinador que incide a ênfase, como garantia de concretização da ação narrativa em causa, o aprender, seja pela abertura do percurso, na manipulação que dota o Sujeito-aluno de um querer-fazer, uma vez que ela deve se pautar pelos conhecimentos, pela experiência e pelos significados que 
eles trazem à sala de aula, suas capacidades e interesses, seja pelo fechamento desse percurso, por meio da sanção sobre o fazer realizado; afınal:

[...] o Destinador é aquele que comunica ao Destinatário-sujeito [...] não somente os elementos da competência modal, mas também o conjunto dos valores em jogo; é também aquele a quem é comunicado o resultado da performance do Destinatário sujeito, que Ihe compete sancionar. (GREIMAS; COURTÉS, 2008, p. 132).

O professor não pode ser considerado, então, um "auxiliar" no processo de ensinoaprendizagem, o que semioticamente falando o colocaria na função actancial de Adjuvante; ele é, na verdade, um Destinador ativo, porque incoativo, promotor do movimento e da ação, e transcendente, porque "paira sobre todas as operações executadas e as paixões vividas pelo sujeito ao longo de sua trajetória [de aprendizagem] [...] É por seu intermédio, pela força transitiva de sua atuação, que as narrativas não param" (TATIT, 2010, p. 20). Ademais, conforme assinala Tatit (2010, p. 24), sendo "responsável pela obstinação do progresso narrativo: além de desencadear a ação, cumpre a esse destinador [transcendente] acompanhá-la à distância e intervir toda vez que houver ameaça à sua continuidade".

Definir a prática didática do professor como uma "ajuda" ao processo de ensinoaprendizagem é relegar a um plano secundário as meta-atuações próprias do fazerfazer. A atuação docente não se configura a partir de um programa narrativo de uso, sendo antes etapa-chave do programa narrativo de base, na manipulação, na aquisição de competência e na sanção. Enquanto Destinador (manipulador e julgador), é no professor que se concentra a força sintáxica do percurso, assegurando a passagem, a transformação de um estado a outro, da disjunção do aluno com certo saber à conjunção; afınal, o Destinador é o "sujeito responsável pela alteração das qualidades do sujeito da ação [...] é aquele que determina a competência e os valores do sujeito que age, aquele que, em suma, estabelece as regras do jogo" (BARROS, 2001, p. 18).

O que está na base da transformação da prática didática é, por conseguinte, um rearranjo da função actancial dos atores nela envolvidos e, consequentemente, na dinâmica da estrutura narrativa que subjaz à coerência sintagmática da interação, responsável pelo efeito de sentido de "horizontalidade" em ato entre os três polos da relação didática: o professor, os alunos e os saberes em jogo; nesta última, o fazer-ser cede lugar ao fazerfazer.

A simetria de lugares, de funções, é, pois, efeito de sentido produzido em uma prática na qual a relação hierárquica entre professor e aluno é fundante, base contratual, fiduciária, do contexto de ensino-aprendizagem. O que muda de fato na condução da prática didática cotidiana é a relevância dada agora à aprendizagem como etapa de competencialização. 
Trata-se do que Greimas e Courtés (2008, p. 75, grifo dos autores) vão chamar de "problemática do ato", explicando: "se o ato é um 'fazer-ser', a competência é 'aquilo que faz ser', vale dizer, todas as preliminares e os pressupostos que tornam a ação possível".

Por isso, não é mais o aluno que deve se adequar ao estilo do professor, a sua prática didática programada, mas é este último quem precisa se ajustar à forma de vida de seus alunos, a sua existência modal, como condição ao diálogo, à eficiência de sua atividade docente, à manipulação pelo querer-fazer, que os levará a agir. Nas palavras de Greimas (1979, p. 7, tradução nossa4), "o discurso didático programado, uma vez estabelecido, deve então sofrer uma modalização que o transforme em discurso persuasivo", tendo em vista "as motivações modais complexas que o discurso persuasivo está encarregado de instituir para formar não somente o 'prazer de aprender', mas também o 'gosto pelo ofício' aprendido e, de modo mais geral, o gosto pela vida e pela ação" (GREIMAS, 1979, p. 7, tradução nossa ${ }^{5}$.

O regime da manipulação, dirigido por um princípio geral de intencionalidade, apresentase, assim, como o elemento-chave da interação didática nessa perspectiva renovada da ação didática. De acordo com Landowski (2014, p. 32):

[...] interagir desse modo é, portanto, em primeiro lugar, atribuir ao outro ou nele reconhecer uma 'vontade' e, a partir daí, procurar pesar sobre suas razões de agir: é tentar fazê-lo querer isso e não aquilo, de modo que - de bom grado [...] - não possa deixar de querer executar o que se planeja a seu respeito.

Mostra-se aí mais um elemento caracterizador da relação hierarquizada entre os atores envolvidos, o professor e seus alunos, mas que mantém, todavia, o efeito de sentido de horizontalidade, por fundamentar-se em uma conduta estratégica que visa ao acordo entre as vontades, uma manipulação de ordem intersubjetiva (LANDOWSKI, 2014). Esse é um outro aspecto da renovação da prática didática, que deve, então, para criar condições significativas de ensino-aprendizagem, fundamentar sua ação em uma pedagogia culturalmente sensível (ERICKSON, 1989), atenta à articulação entre a cultura que os alunos trazem de casa e à cultura da escola.

A prática didática do professor precisa, pois, ser da ordem do ajustamento mais do que da programação; o que intensifica, como dissemos, o efeito de uma interação mais horizontal

4 No original: "Le discours didactique programmé, une fois établi, doit donc subir une modalisation qui le transforme en discours persuasif.".

5 No original: "[...] des motivations modales complexes que le discours persuasif est chargé d'instituer pour former non seulement le 'plaisir d'apprendre', mais aussi le 'gôut du métier' appris et, plus généralement, le gôut de la vie et de l'action.". 
e menos verticalizada, mais participativa, porque mais dialógica; um fazer conjunto. Vale dizer, no entanto, que essa interação regida pelo ajustamento fica a serviço do regime de manipulação, uma vez que, de acordo com Landowski (2014, p. 33):

[...] se o estrategista-manipulador [Destinador] reconhece o querer do outro e, melhor ainda, se se dedica a conhecê-lo em profundidade, a torná-lo tão transparente quanto possível, a detectar suas determinações [...], é unicamente para manipulá-lo com maior segurança, para ganhar mais poder sobre ele, atuando sobre suas motivações e suas razões.

É por isso que o semioticista, em um outro texto seu dedicado à discussão sobre os regimes de sentido e as formas de educação (LANDOWSKI, 2016, p. 10, grifos do autor), vai insistir que:

De fato, se admitido que o ato de educar põe por definição em relação de interação um sujeito-educador (educator), um sujeito-"educável" (a educar, educandum, e não "educado", termo resultativo) e um objeto-educante (educans, matéria cujo domínio, sob forma de utilização ou de prática, fará um dia do educável um educado), então a diversidade de práticas educativas, assim como as causas dos problemas que elas levantam, deveriam ser analisáveis a partir da distinção [...] entre um pequeno número de regimes de interação fundados sobre princípios semióticos interdefinidos (princípios de regularidade vs. de aleatoriedade, de intencionalidade vs. de sensibilidade), os quais, eles mesmos, remetem a outros tantos regimes de sentido (programação, assentimento face ao inevitável, manipulação, ajustamento ao outro).

Para Landowski (2016, p. 11), "as posições do educator e do educandum aí parecem intercambiáveis, e correlativamente o educans (a "matéria" a ensinar) perde seu caráter tradicional de saber objetivado para vir a se confundir com o próprio processo interacional". Desse ponto de vista, no regime de interação regido pelo ajustamento, os envolvidos, "sentindo a maneira de agir um do outro, vão construindo in fieri os princípios da relação" (LANDOWSKI, 2016, p. 9). Dessa forma, ao contrário da interação didática de ordem programática, "quando, para chegar a seus fins, é suficiente que o ator se apoie em certas determinações preexistentes, estáveis e cognoscíveis, do comportamento do outro" (p. 48), a interação por ajustamento supõe "que o parceiro com o qual se interage e com que, no caso, tenta ajustar-se, seja tratado como um actante sujeito de pleno direito, e não como uma coisa de comportamento estritamente programado" (p. 49).

Choca-se, desse modo, perante esse aspecto da transformação didática, essa nova postura a qual deve assumir o professor e a manutenção da situação de aula em um ambiente estruturado e altamente programado, com formas de interação previamente fixadas, num processo centrado na rigidez dos métodos e programas ali inscritos, com 
atividades restritas aos livros didáticos e apostilas, sem respeito ao ritmo de aprendizagem do aluno. Essa tensão lança luz ao desafio a ser vencido: os obstáculos que impedem o professor de se ajustar aos seus alunos, pelo contexto didático-pedagógico que continua na ordem da programação, dirigido por um "currículo de resultados" (LIBÂNEO, 2016), com dispositivos de regulação cada vez mais cerceadores.

De toda forma, ainda que esse desajuste seja, de fato, um grande problema colocado à efetiva renovação da prática didática, desvelando a incoerência da relação entre o que se prega e o modo como se põe em prática, não se pode perder de vista "como uma luz no fim do túnel - que na sala de aula se cruzam práticas que podem corresponder, simultaneamente ou alternadamente, a qualquer um dos regimes" (LANDOWSKI, 2016, p. 11), pois, "de fato, nas suas interações, educator, educandum e educans não se conduzem necessariamente uns e outros segundo os princípios diretores de um único e mesmo regime interacional" (p. 11); isso porque a relação didática precisa ser conduzida ao modo de uma "acomodação estratégica" - nos termos de Fontanille (2007) e Landowski (2014) - entre modos de ser e de fazer distintos, entre diferentes estilos de vida e modos de coexistência, entre visões de mundo diversas.

Nesse sentido, a prática didática ideal é aquela que gerencia (estrategicamente), na situação cotidiana de aula, os quatro modelos narrativos (um regido por uma lógica da regularidade; outro, por uma lógica da eventualidade; outro ainda, por uma lógica da intencionalidade; e, por último, um, por uma lógica da sensibilidade) subjacentes aos quatro regimes de interação landowskinianos (da programação, do acidente (ou acaso), da manipulação e do ajustamento, respectivamente), deslizando de um estilo a outro conforme a demanda colocada ${ }^{6}$. Conforme explica Landowski (2014, p. 31), "na verdade, entre esses regimes, a teoria define transições, assim como prevê múltiplas superposições e combinações possíveis. No plano das práticas, elas são mesmo a regra".

\section{Da competencialização semântica à modal: o problema da avaliação}

Greimas, em uma entrevista sobre o ensino concedida a Jacques Fontanille em 1984, publicada no número 61 da revista Langue Française, afirma que "o que caracteriza o discurso didático é a 'competencialização"' (FONTANILLE, 1984, p. 124, tradução nossa7), justificando-se: "uso esse termo grosseiro com algumas ressalvas, mas ele descreve perfeitamente essa operação de aumento desejado e programado da competência, o que me parece especificamente didático" (p. 124, tradução nossa ${ }^{8}$ ). Ele acrescenta: "É,

6 Para um aprofundamento sobre os quatro tipos aqui elencados, consultar Landowski (2014).

7 No original: "Je crois que ce qui caractérise le discours didactique, c'est la 'compétentialisation"'.

8 No original: "J'emploie ce terme barbare avec un peu de réticence, mais il décrit parfaitement cette opération d'augmentation voulue et programmée de la compétence qui me semble spécifiquement didactique.". 
acredito, o que permite distinguir a didática em meio aos demais discursos persuasivos" (p. 124, tradução nossa9 ${ }^{9}$.

No que diz respeito aos objetivos de ensino, podemos dizer, pois, que a renovação didática em pauta caracteriza a passagem de uma prática com vistas à competencialização semântica do aluno a uma outra que deve se preocupar antes de mais nada com sua competencialização modal. Como explica Greimas (1979, p. 4, tradução nossa ${ }^{10}$ ), "tal classificação procura dar definições semióticas precisas aos objetos de valor visados pelos programas narrativos subjacentes ao discurso didático". Na primeira, considerada em si mesma como "conteúdo" (GREIMAS; COURTÉS, 2008, p. 76), "correspondendo à definição tradicional de ensino como transferência de 'conhecimento'" (GREIMAS, 1979, p. 6, tradução nossa"1), a aquisição de competência será conteudística. Na segunda, "o sujeito já competente é chamado a 'agir', a exercer o saber-fazer adquirido" (p. 5, tradução nossa ${ }^{12}$ ); daí que, para o autor (p. 5, tradução nossa ${ }^{13}$ ), "por /saber-fazer/, designamos em semiótica um componente modal da competência geral que, enquanto 'inteligência sintagmática', torna o sujeito capaz de realizar quaisquer PN (programas narrativos), frequentemente complexos".

É justamente essa a ideia que subjaz ao discurso em defesa do "aprender a aprender", ou, em segunda instância, do "fazer aprender" que, de acordo com Fabbri (1979, p. 9, tradução nossa ${ }^{14}$ ), "significa, no fundo, atribuir ao aluno qualificações que o tornem um receptor competente frente aos objetos cognitivos que Ihe são transmitidos: competência ligada, portanto, não somente à reprodução do saber, mas também a sua própria aquisição e evolução".

9 No original: "C'est, je crois, ce qui permet de distinguer la didactique à l'intérieur des autres discours persuasifs.".

10 No original: "Une telle classification cherche à donner des définitions sémiotiques précises des objets de valeur que doivent viser les programmes narratifs sous-jacents aux discours didactiques".

11 No original: "[...] correspondant à la définition traditionnelle de l'enseignement comme transfert de 'connaissances' [...]".

12 No original: "[...] le sujet déjà compétent est appelé à 'performer', à exercer le savoir-faire acquis.".

13 No original: "[...] par /savoir-faire/, on désigne en sémiotique une composante modale de la compétence générale qui, en tant qu"intelligence syntagmatique', rend le sujet capable de procéder à la réalisation des PN (programmes narratifs) quelconques, souvent complexes.".

14 No original: "[...] 'faire-apprendre' signifie, plus profondément, attribuer à l'enseigné les qualifications qui en feront un récepteur compétent à l'égard des objets cognitifs qui lui sont transmis : compétence relative, par conséquent, non seulement à la reproduction du savoir, mais aussi à son acquisition même, et à son évolution.". 
Nesse ponto de vista, onde o que importa é, sobretudo, o desenvolvimento de habilidades e competências de leitura e escrita variadas, o objetivo de ensino-aprendizagem passa a ser um enunciado composto pelas seguintes unidades (FONTANILLE, 2016, p. 16):

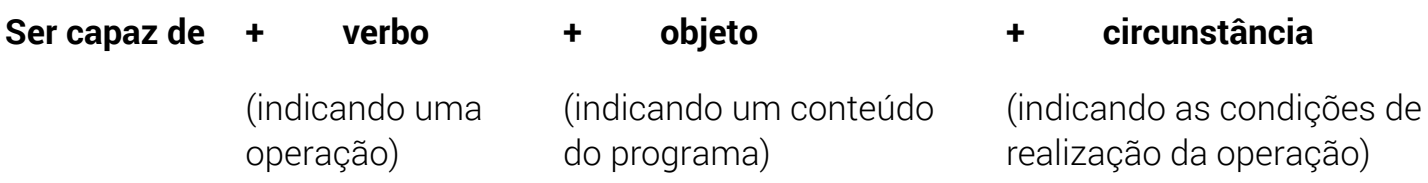

Segundo Fontanille (2016, p. 16, grifo do autor), "esse enunciado formula, portanto, uma competência para um fazer preciso e circunstanciado", uma vez que "um objetivo não é dito operacional a menos que corresponda a uma atividade concreta, definindo um 'comportamento observável"; por isso, assinala o autor, "não se trata então [apenas] de competência, mas de performance [em ato]" (FONTANILLE, 2016, p. 16, grifo do autor). Essa mudança de postura na condução do processo (narrativo) de ensino-aprendizagem impõe, igualmente, uma alteração na forma de avaliação do aluno, ou seja, na sanção sobre sua performance. Se mudam os objetivos de ensino, mudam também os resultados esperados, logo, devem ser outros os critérios de julgamento, de sanção.

Dentro do ponto de vista dessa prática didática renovada, o professor, como Destinadorjulgador do percurso, deve passar a trabalhar com três diferentes formas (aspectuais) de avaliação: (i) uma diagnóstica (ou preditiva), que permitirá a ele saber quais são as aquisições anteriores dos alunos e as lacunas a preencher, para, a partir daí, decidir as habilidades a adquirir, e a melhor forma de desenvolvê-las; (ii) uma formativa (a prova qualificante), que permite "sondar" o aprendiz em curso de aprendizagem, e a partir daí modificar a abordagem, rever as atividades criadas etc.; e, por fim, (iii) uma somativa (a principal), que sanciona, de fato, no fim do percurso, o sucesso ou a falha da performance, do percurso de ação como um todo (FONTANILLE, 2016).

A primeira instituia falta eassimajuda na definição da ação do professor, no seu ajustamento às necessidades de aprendizagem dos alunos; é o momento em que o professor avalia o que o aluno já sabe sobre determinado conteúdo para, a partir daí, estruturar sua programação. O segundo tipo de avaliação, por sua vez, possibilita a verificação do andamento do processo e da eficácia das condições de aquisição de competência, apontando os ajustes necessários. Pode ser concebida como uma avaliação contínua do processo. Já a terceira permite avaliar não apenas a performance realizada, mas o próprio estado juntivo resultante do processo de ensino-aprendizagem como um todo; averigua tanto a construção do conhecimento por parte dos alunos, quanto a eficiência dos objetivos a que o professor se propôs. Nestas duas últimas, não só o professor é o Destinador-julgador, mas também o próprio aluno, para tomada de consciência de seus avanços, dificuldades e possibilidades de maior envolvimento na tarefa de aprender. 
A avaliação, como sanção de todo processo de ensino-aprendizagem, deve, portanto, incidir sobre a performance do aluno na sua relação com o saber, e não mais sobre o conhecimento em si. Ela deve avaliar, a partir da performance realizada, a competência adquirida e demonstrada na situação de avaliação, lembrando que é responsabilidade do Destinador do percurso estabelecer as condições favoráveis a sua realização, uma vez que a ele cabe o fazer-fazer; isto é, se há falhas na realização da performance, o problema pode estar nas estratégias adotadas que não garantiram a aquisição de competência, não levaram ao poder e saber-fazer; e não unicamente no aluno.

\section{Para concluir}

Os apontamentos feitos nesse esforço de inteligibilidade da tão reivindicada transformação da prática didática na Educação Básica mostram, em resumo, que na base da mudança está uma reorganização da sua estrutura narrativa, mais especificamente das funções actanciais que a dinamizam, e da ênfase dada às duas unidades do sintagma ensino-aprendizagem, estabelecendo um efeito de horizontalidade entre elas. Da aula como percurso do ensinar, da performance do Sujeito-professor, passa-se ao percurso do Destinador-professor, enquanto Destinador transcendente, responsável pela manutenção do processo, pela criação das condições de realização da performance de aprendizagem operada pelo Sujeito-aluno. Passa-se, dessa forma, da programação ao ajustamento servindo à manipulação, do monólogo ao diálogo, à construção conjunta de habilidades e competências.

Ao contrário do que deixam entender alguns discursos ${ }^{15}$, fica claro, portanto, que a função do professor em sala de aula continua a ser de fundamental importância para a eficiência do processo de ensino-aprendizagem como etapa de competencialização modal; ela é o "ser do fazer" (BARROS, 2001, p. 51), colocando-lhe, dentro dessa nova configuração narrativa, ainda mais responsabilidade e desafios, uma vez que é preciso deixar de encarar o conteúdo pelo conteúdo, muitas vezes dissociado de competências, privilegiando a aprendizagem do modo de lidar com eles, do seu uso consciente, da busca, da seleção, da articulação, da interpretação e da produção críticas de conhecimentos. Abandonar a postura didática monológica e programada da transmissão, para adotar uma atitude dialógica, de ajustamento em ato, na interação viva entre os atores envolvidos nesse processo de construção do Objeto-valor buscado, é o que caracteriza a mudança de postura didática requerida, assegurada pela compreensão de que "a estruturação da aula é um processo que implica criatividade e flexibilidade do professor, isto é, a perspicácia de saber o que fazer frente a situações didáticas específicas, cujo rumo nem sempre é previsível" (LIBÂNEO, 2013, p. 197).

15 Estamos nos referindo aqui aos discursos mais recentes sobre as "metodologias ativas", tal como têm sido "vendidos", sobretudo, às instituições particulares de ensino. 
Todavia, é justamente esse entendimento sistemático daquilo que concerne a tal transformação o que nos permite perceber de maneira mais evidente que, mais do que uma renovação efetiva da prática didática, estamos diante de um processo aberto, de reestruturação progressiva e desacelerada, ainda em curso de concretização. O que de fato mudou - sendo já este um grande primeiro passo - foi, sobretudo, o discurso sobre como deve ser o funcionamento da atividade docente, permanecendo a sua implementação prática um desafio, por exemplo, à formação inicial e continuada de professores.

Uma forma possível de dissolução desse impasse, no entanto, está na contínua (e necessária!) conscientização do professor em relação à centralidade de seu papel como agente por excelência da ação educativa, a sua posição privilegiada frente à concretização dos interesses em jogo na sociedade. É essa convicção, exercida no âmbito de uma ação didática social e política, que deve alimentar o seu compromisso com a aprendizagem concreta, com uma formação, enfım, verdadeiramente democrática, cidadã e inclusiva.

\section{Agradecimentos}

Este texto é parte dos resultados de uma pesquisa financiada pela FAPESP (Processo n. 2017/14300-7).

\section{REFERÊNCIAS}

BARROS, D. L. P. Teoria do discurso. Fundamentos Semióticos. São Paulo: Humanitas, 2001.

ERICKSON, F. Métodos cualitativos de investigación sobre la enseñanza. In: WITTROCK, M. C. (org.). La investigación de la enseñanza, II. Barcelona: Paidos, 1989. p. 195-301.

FABBRI, P. Champ de manoeuvres didactiques. Le Bulletin, n. 7, p. 9-14, 1979.

FONTANILLE, J. Para mudar, começar pelo fim: digressão sobre a racionalidade didática. EntreLetras, v. 7, n. 2, p. 15-18, 2016. Disponível em: https://sistemas.uft.edu.br/ periodicos/index.php/entreletras/article/view/3203/9476. Acesso em: 13 jun. 2020.

FONTANILLE, J. Pratiques sémiotiques. Paris: PUF, 2007.

FONTANILLE, J. Entretien. Langue française. Sémiotique et enseignement du français, Larousse, n. 61, p. 121-128, 1984.

GREIMAS, A. J. Pour une sémiotique didactique. Le Bulletin, n. 7, p. 3-8, 1979. 
GREIMAS, A. J.; COURTÉS, J. Dicionário de semiótica. São Paulo: Contexto, 2008.

HOUAISS, A. Dicionário eletrônico Houaiss da Língua Portuguesa. Rio de Janeiro: Objetiva, 2009.

LANDOWSKI, E. Regimes de sentido e formas de educação. EntreLetras, v. 7, n. 2, p. 8-14, 2016. Disponível em: https://sistemas.uft.edu.br/periodicos/index.php/entreletras/ article/view/3201/9472. Acesso em: 25 jun. 2020.

LANDOWSKI, E. Interações arriscadas. São Paulo: Estação das Letras e Cores, 2014.

LIBÂNEO, J. C. Políticas educacionais no Brasil: desfiguramento da escola e do conhecimento escolar. Cadernos de Pesquisa, v. 46, n. 159, p. 38-62. 2016.

LIBÂNEO, J. C. Didática. São Paulo: Cortez, 2013.

LIBÂNEO, J. C. Ensinar e aprender, aprender e ensinar: o lugar da teoria e da prática em didática. In: LIBÂNEO, J. C.; ALVES, N. (org.). Temas de pedagogia: diálogos entre didática e currículo. São Paulo: Cortez Editora, 2012.

LIBÂNEO, J. C. Adeus professor, adeus professora? Novas exigências educacionais e profissão docente. São Paulo: Cortez, 2011.

PORTELA, J. C. Práticas didáticas: um estudo sobre os manuais brasileiros de semiótica greimasiana. 2008. Tese (Doutorado em Linguística e Língua Portuguesa) - Faculdade de Ciências e Letras, Universidade Estadual Paulista, Araraquara, 2008.

TATIT, L. Semiótica à Luz de Guimarães Rosa. São Paulo: Ateliê Editorial, 2010. 